\title{
Vasculitis damage index in Behçet's disease
}

\author{
Fatema T. Elgengehy ${ }^{1 *}$ (D), Sherif M. Gamal ${ }^{1}$, Nesreen Sobhy', Ibrahem Siam², Ahmed M. Soliman³, \\ Ghada W. Elhady ${ }^{4}$ and Tamer A. Gheita'
}

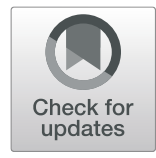

\begin{abstract}
Background: Vasculitis damage index (VDI) is a validated damage index for systemic vasculitis, and as Behçet's disease is considered one of systemic vascular disease we aimed to study the relationship of the vasculitis damage index to clinical manifestations and comorbidity in patients with Behçet's disease (BD) to determine if VDI could be used to assess damage in patients with BD.

Methods: A total of 109 patients with BD were recruited from the Rheumatology Department (outpatient and inpatient clinic), Cairo University Hospitals. All patients were subjected to full history taking, clinical examination, and routine laboratory investigations. Disease activity was assessed by the BD current activity form, and the VDI was calculated in all patients. The relationship of the VDI to the disease clinical manifestations was studied. MannWhitney and Kruskal Wallis tests were used to estimate differences in quantitative variables. Spearman correlation test was used to test for correlation between quantitative variables.
\end{abstract}

Results: In the current study, the VDI ranged from 1 to 10 , with a mean of $3.5 \pm 1.8$. It was significantly associated with total thrombosis $(P=0.022)$; total neurological manifestations $(P=0.000)$, especially stroke and cranial nerve affection; uveitis $(P=0.005)$; avascular necrosis (AVN) $(P=0.015)$; osteoporosis $(P=0.01)$; impaired vision $(P<0.0001)$; cataract $(P<0.0001)$; and diabetes $(P=0.012)$. Generally, immunosuppressive treatment was significantly associated with VDI $(P=0.039)$, especially cyclophosphamide $(P<0.0001)$, biological agent $(P=0.008)$, chlorambucil $(P=0.003)$, and anticoagulant $(P=0.02)$. VDI was also significantly correlated with age $(P=0.033)$, disease duration $(P=0.029)$, and duration of eye involvement $(P=0.003)$.

Conclusion: VDI is significantly associated with most disease parameters of $\mathrm{BD}$, except for parameters such as mucocutaneous manifestations and uncomplicated venous thrombosis; however, further studies may be needed to establish BD-specific damage index.

Keywords: Vasculitis damage index, Behçet's disease, Egyptian Patients

\section{Background}

Behçet's disease $(\mathrm{BD})$ is a multisystem, inflammatory, autoimmune disease with unknown etiology and pathogenesis and unpredictable prognosis [1,2]. BD is classified among systemic vasculitides [3]. Vascular involvement is a common finding in BD, which is significantly associated with higher morbidity and mortality rates, and may affect up to $40 \%$ of patients with BD, mostly in the form of deep venous thrombosis (DVT) and superficial thrombophlebitis [4-6]. Arterial vascular involvement is less frequent

\footnotetext{
*Correspondence: fatematalaat1980@yahoo.com

${ }^{1}$ Rheumatology and Rehabilitation Department, Cairo University, Cairo, Egypt Full list of author information is available at the end of the article
}

than venous affection in BD; however, the prognosis is poorer in such cases [7]. Furthermore, recent data also verified the presence of accelerated classical subclinical arterial damage, such as arteriosclerosis, even in patients without overt vascular complications and may be complementary to that of vasculitis [1].

The prognosis for a patient with systemic vasculitis has improved with treatment $[8,9]$. However, the longterm outlook may be associated with accumulation of damage, from recurrent flares or treatment $[9,10]$. Careful differentiation between activity and damage is mandatory to prevent unnecessary exposure to cytotoxic medications. Damage significantly influences both long-

(c) The Author(s). 2021 Open Access This article is licensed under a Creative Commons Attribution 4.0 International License, which permits use, sharing, adaptation, distribution and reproduction in any medium or format, as long as you give appropriate credit to the original author(s) and the source, provide a link to the Creative Commons licence, and indicate if changes were made. The images or other third party material in this article are included in the article's Creative Commons licence, unless indicated otherwise in a credit line to the material. If material is not included in the article's Creative Commons licence and your intended use is not permitted by statutory regulation or exceeds the permitted use, you will need to obtain permission directly from the copyright holder. To view a copy of this licence, visit http://creativecommons.org/licenses/by/4.0/. 
term prognosis and quality of life, so systemic recording of damage may be helpful in improving treatment decision and predicting disease outcomes $[1,10]$.

A well-established validated damage index, "vasculitis damage index" (VDI) [11], is currently the most widely used assessment tool for damage in vasculitis. It is based on a score derived from individual items from disease onset and comprises 64 items (grouped into 11 organbased systems). The items were originally selected by consensus among experienced physicians. Damage was defined by three key characteristics: irreversibility, presence for $>3$ months, and attribution of the lesion to vasculitis or its therapy. Each item was not weighted; therefore, all items contribute equally to the score. The VDI has been used to demonstrate that irreversible damage occurs early in the disease course and has a significant effect on subsequent morbidity and mortality. Multi-organ involvement within 2 years is associated with an increased risk of death [12].

The Outcome Measures in Rheumatology (OMER$\mathrm{ACT}$ ) has defined the core set domain of outcome measures for $\mathrm{BD}$, and concluded that both measures of disease activity and damage should be included, as separate and complementary entities, into the core outcome set for BD [13]. However, no BD damage index had been developed until 2020, when Piga et al. published the first BD damage index (BODI) and validated it through several steps, one of which was the correlation with VDI, and they concluded that pending further validation still required [14]. Thus, this study aimed to evaluate the relationship of the VDI to clinical manifestations and comorbidities in patients with BD. Our study may be a preliminary study to assess if VDI is suitable tool for damage assessment in patients with $\mathrm{BD}$.

\section{Patients and methods}

This cross-sectional study included 109 adult patients with BD (98 men and 11 women [8.9:1]). Patients were recruited consecutively (with exclusion of juvenile onset BD patients), from 2016 to 2018, from the Rheumatology Department (inpatient and outpatient clinic) of Cairo University Hospitals, Egypt. All patients met the criteria of the International Study Group for BD [3]. Patients were subjected to full history taking, thorough clinical examination and all clinical manifestations were assessed if ever happened in the disease course, either acute or chronic or both. Routine laboratory tests and relevant medications used were recorded. The treatment protocol of our patients was generally in accordance with 2008 and 2018 EULAR recommendations $[15,16]$, with few modifications due to financial issues or special case situations.

In the present study, disease activity was assessed for all patients by BD current activity form (BDCAF) by filling the items of the BDCAF according to the information provided by the patients and current medical reports [17], while VDI was also calculated for each patient at the time of recruitment [11]. A comparative and correlative study of the VDI of our patients was conducted with respect to different disease parameters. It is to be noted that medical records of Behçet's patients who died during the period of the study were reviewed for the previously mentioned data. The study was performed in accordance with the Declaration of Helsinki and approved by the local ethical committee. Informed consent was obtained from all patients before their enrollment in the study.

\section{Statistical analysis}

Data were processed and analyzed using the Statistical Package for the Social Sciences (SPSS) software version 15 for Windows (SPSS Inc., Chicago, Illinois, USA). For quantitative variables, median (minimum, maximum, inter quartile range $(\mathrm{IQR})$, or mean $( \pm \mathrm{SD})$ were used. Frequency and percentage were presented for qualitative variables. Mann-Whitney and Kruskal Wallis tests were used to estimate differences in quantitative variables. Spearman correlation test was used to test for correlation between quantitative variables. A $P$-value $<0.05$ indicated statistical significance.

\section{Results}

In the current study, the age of our patients ranged from 18 to 58 years, with a mean of $35.3 \pm 8$ years. Moreover, 98 patients were male, and 11 were female (8.9:1). Oral ulcers were reported in $94.5 \%$ of patients, genital ulcers in $85.3 \%$, uveitis in $69.7 \%$, skin lesions in $39.4 \%$, and vascular involvement in $50.5 \%$. Demographic and clinical data of our patients are shown in Table 1. Medications received by patients with BD are shown in Table 2 .

VDI in the current study ranged from 1 to 10 , with a mean of $3.5 \pm 1.8$, and was significantly associated with major organ damage including; total thrombosis, total neurological manifestations (especially stroke and cranial nerve affection), eye manifestations (uveitis, visual impairment, cataract), and disease-related complications or associated comorbidities (avascular necrosis [AVN], osteoporosis, and diabetes). The use of immunosuppressive drugs in general was significantly associated with VDI, especially cyclophosphamide, biological agent, chlorambucil, and anticoagulant. VDI was also significantly correlated with age, disease duration $(P=0.029)$, and duration of eye involvement. Details of association of VDI to different disease variables are shown in Tables 3 and 4. Correlation of VDI score with clinical variables is shown in Table 5.

\section{Discussion}

$\mathrm{BD}$ is a chronic autoimmune systemic vasculitis with an obscure pathogenesis [18]. Vasculitis of BD can involve 
Table 1 Demographic and clinical data of patients with BD

\begin{tabular}{|c|c|}
\hline Parameter & Patients with BD $(n=109)$ \\
\hline Age, mean \pm SD (range) & $35.3 \pm 8(18-58)$ years \\
\hline Sex, male:female & $98: 11(8.9: 1)$ \\
\hline $\begin{array}{l}\text { Disease duration, median, minimum, } \\
\text { maximum, IQR }\end{array}$ & $9,1,38,8.5$ years \\
\hline $\begin{array}{l}\text { Delay in diagnosis, median, minimum, } \\
\text { maximum, IQR }\end{array}$ & $12,0.2,216,48$ months \\
\hline BDCAF grades 0/1/2/3 & $50 / 45 / 11 / 3$ \\
\hline Oral ulcers, n(\%) & $103(94.5)$ \\
\hline Genital ulcers, n(\%) & $93(85.3)$ \\
\hline Skin lesions, n(\%) & $43(39.4)$ \\
\hline Eye (uveitis), n(\%) & $76(69.7)$ \\
\hline $\begin{array}{l}\text { Duration of eye affection, } \\
\text { mean } \pm \text { SD (range) }\end{array}$ & $86.7 \pm 60.1(2-264)$ months \\
\hline Impaired vision, n(\%) & $62(56.9)$ \\
\hline Blindness, n(\%) & $12(11)$ \\
\hline Cataract, n(\%) & $40(36.7)$ \\
\hline Vascular involvement, n(\%) & $55(50.5)$ \\
\hline DVT, n(\%) & $29(26.6)$ \\
\hline DVT (no. of attacks), n(\%) & $\begin{array}{l}\text { Once } 9(8.3) \text { or twice } 20 \\
(18.3)\end{array}$ \\
\hline Thrombosis (arterial/venous), n(\%) & $52(47.7)$ \\
\hline Thrombosis (no. of attacks), n(\%) & $\begin{array}{l}\text { Once } 27 \text { (24.8) or twice } 25 \\
(22.9)\end{array}$ \\
\hline Aneurysms, n(\%) & $14(12.8)$ \\
\hline Neurological involvement, n(\%) & 19 (17.4) \\
\hline Cranial nerve affection, n(\%) & $12(11)$ \\
\hline Ataxia, n(\%) & $3(2.8)$ \\
\hline Coma, n(\%) & $1(0.9)$ \\
\hline Stroke, n(\%) & $9(8.3)$ \\
\hline Arthritis, n(\%) & $12(11)$ \\
\hline AVN, n(\%) & $4(3.7)$ \\
\hline Osteoporosis, n(\%) & $7(6.4)$ \\
\hline Diabetes, n(\%) & $8(7.3)$ \\
\hline Mortality, n(\%) & $8(7.3)$ \\
\hline VDI & $3.5 \pm 1.8(1-10)$ \\
\hline
\end{tabular}

$B D$ Behçet's disease, $B D C A F$ BD current activity form, DVT Deep venous thrombosis, AVN Avascular necrosis, VDI Vasculitis damage index

any type and size of vessels, which explains why the disease has the ability of multi-systemic involvement [19], which could lead to serious morbidity and mortality [18].

In conditions associated with systemic vasculitis, a comprehensive assessment of disease severity should include measurements of disease activity, damage, and functional status. Damage develops as a consequence of recurrent or persistent active disease or its treatment and is defined as the accumulation of non-healing scars
Table 2 Medications received by patients with Behçet's disease

\begin{tabular}{ll}
\hline Medications & Patients with BD ( $\mathbf{n = 1 0 9 )}$ \\
\hline Cyclophosphamide, n (\%) & $61(56)$ \\
Azathioprine, n (\%) & $62(56.9)$ \\
Cyclosporine A, n (\%) & $39(35.8)$ \\
Biologic therapy, n (\%) & $22(20.2)$ \\
Colchicine, n (\%) & $2(1.8)$ \\
MMF, n (\%) & $1(0.9)$ \\
Chlorambucil, n (\%) & $3(2.8)$ \\
Leflunomide, n (\%) & $1(0.9)$ \\
Anticoagulants, n (\%) & $40(36.7)$ \\
\hline
\end{tabular}

$B D$ Behçet's disease, MMF Mycophenolate mofetil

that are unlikely to respond to immunosuppressive therapy [20]. Therefore, a damage index is needed to quantify damage, aid in the separation of damage from disease activity, and rationalize selection of therapy.

In the current study, the male/female ratio was quite high (8.9:1). This may be similar to some previous studies conducted on patients with BD in Egypt [21, 22]. In addition, our university is a tertiary referral hospital, receiving severe cases including vascular involvement, which has a higher frequency of male patients [23].

Thrombosis is the most frequent vascular manifestation in $\mathrm{BD}$ and an important factor of poor prognosis [24]. A study performed by Gerco et al. in 2018 revealed that the major causes of morbidity and mortality rates in $\mathrm{BD}$ result from ocular, major vascular, and neurological involvement [25].

Amigo et al. reported that thrombotic events that are considered the hallmark of antiphospholipid syndrome may cause irreversible damage from the onset of the disease. In our opinion, this is also applicable for BD and may explain the association of thrombosis and VDI [26].

In addition, most neurological manifestations and part of the total thromboses are caused by arterial affection, which was found to be associated with greater mortality rate $(13.5 \%$ in patients with $\mathrm{BD}$ with arterial lesions compared to $3.6 \%$ in those without arterial involvement) [27].

The association of VDI with uveitis and its complication may also be predictable, if we consider that ocular inflammation develops in approximately $70 \%$ of patients and refractory ocular inflammation that may lead to blindness is common in those not responding well to systemic corticosteroids combined with other immunosuppressive agents observed in patients with BD [28].

Osteoporosis, AVN and diabetes; these specific damage items are shared by different damage indices as SLIC $C$ for lupus [29] and even VDI itself because they commonly result from high cumulative doses of glucocorticoids used for the treatment of different manifestations 
Table 3 Comparison of Vasculitis Damage Index (VDI) with respect to demographic and clinical manifestations

\begin{tabular}{llll}
\hline & VDI score & & \\
\cline { 2 - 3 } & Minimun-Maximum & Median (IQR) & $P$-value \\
\hline
\end{tabular}

\begin{tabular}{llll}
\hline Sex & & & \\
Male & $1-10$ & $3(2)$ & $0.1^{*}$ \\
Female & $1-7$ & $5(2)$ &
\end{tabular}

\section{Oral ulcers}

$\begin{array}{lll}\text { Yes } & 1-10 & 3(3) \\ \text { No } & 1-3 & 3(1)\end{array}$

\section{Genital ulcers}

$\begin{array}{ll}\text { Yes } & 1-10 \\ \text { No } & 1-8\end{array}$

Other skin lesions

Yes 1-8

No $\quad 1-10$

Vascular involvement

$\begin{array}{ll}\text { Yes } & 1-10 \\ \text { No } & 1-7\end{array}$

DVT attacks

Arterial or venous thrombosis

$\begin{array}{ll}\text { Yes } & 1-10 \\ \text { No } & 1-8\end{array}$

\section{Aneurysm}

Neurological affection

$\begin{array}{lll}\text { Yes } & 3-10 & 5(2) \\ \text { No } & 1-8 & 3(2) \\ \begin{array}{l}\text { Cranial nerve } \\ \text { affection }\end{array} & & \\ \text { Yes } & 5-10 & 6(3) \\ \text { No } & 1-8 & 3(2)\end{array}$

Ataxia

$\begin{array}{ll}\text { Yes } & 4-7 \\ \text { No } & 1-10\end{array}$

\section{Stroke}

$\begin{array}{ll}\text { Yes } & 3-6 \\ \text { No } & 1-10\end{array}$

Arthritis

$\begin{array}{ll}\text { Yes } & 1-8 \\ \text { No } & 1-10\end{array}$

AVN
Table 3 Comparison of Vasculitis Damage Index (VDI) with respect to demographic and clinical manifestations (Continued)

\begin{tabular}{llll}
\hline & \multicolumn{2}{l}{ VDI score } & \\
\cline { 2 - 4 } & Minimun-Maximum & Median (IQR) & P-value \\
\hline No & $1-8$ & $3(2)$ & \\
Osteoporosis & & & \\
Yes & $3-10$ & $7(7)$ & $\mathbf{0 . 0 1 *}$ \\
No & $1-8$ & $4(1)$ &
\end{tabular}

Uveitis

Yes

$1-10 \quad 4(3)$

$0.005^{*}$

No $\quad 1-8 \quad 3(2)$

Vision

Normal $\quad 1-8$

Impaired 1-7

Blindness $\quad 2-10$

Cataract

No involvement
Single eye
involvement
Both eye
involvement

Diabetes

Yes
No
N-10

of rheumatic diseases thus it is not surprising to find an association between these damage items and VDI.

Systemic immunosuppressive and biological agents are the standard therapy for severe organ involvement in $\mathrm{BD}$ [30-32], and the goal of management is early treatment to avoid recurrences and irreversible damage to the vital organs [33]. As other autoimmune diseases, medications used may be associated with serious side effects and damage [31, 34, 35]. In our study, the use of immunosuppressive drugs in general was significantly associated with VDI, especially cyclophosphamide, infliximab, and chlorambucil, in addition to anticoagulant, while the use of other medications that may be used in BD for milder presentation, such as colchicine and azathioprine, was not significantly associated with VDI. In our opinion, although such medications may improve survival and disease outcomes, they should be reserved for severe aggressive disease manifestations, as these medications may show some serious side effects, increasing the damage; thus, the association of immunosuppressive drug use and VDI could be expected, also from another point of view such medications may be used to treat active, aggressive disease, which itself may be associated with increased damage. 
Table 4 Comparison of Vasculitis Damage Index (VDI) with respect to the medication received

\begin{tabular}{|c|c|c|c|}
\hline & VDI score & & \\
\hline & Minimun-Maximum & Median (IQR) & $P$-value \\
\hline Immun & opressive drugs & & \\
\hline Yes & $1-10$ & $3(2)$ & $0.039 *$ \\
\hline No & $1-4$ & $3.5(2)$ & \\
\hline CYC & & & \\
\hline Yes & $1-10$ & $4(3)$ & $<0.0001^{*}$ \\
\hline No & $1-7$ & $2.5(1)$ & \\
\hline AZA & & & \\
\hline Yes & $1-10$ & $3(3)$ & $0.294^{*}$ \\
\hline No & $1-8$ & $3(2)$ & \\
\hline CSA & & & \\
\hline Yes & $1-10$ & $3(2)$ & $0.874^{*}$ \\
\hline No & $1-8$ & $3(3)$ & \\
\hline Biologi & & & \\
\hline Yes & $1-10$ & $4(2)$ & $0.008^{*}$ \\
\hline No & $1-8$ & $3(2)$ & \\
\hline Colchic & & & \\
\hline Yes & $2-2$ & $2^{* *}$ & $0.16^{*}$ \\
\hline No & $1-10$ & $3(2)$ & \\
\hline Chlora & & & \\
\hline Yes & $7-10$ & $8^{* *}$ & $0.003^{*}$ \\
\hline No & $1-8$ & $3(2)$ & \\
\hline Antico & & & \\
\hline Yes & $1-10$ & $4(4)$ & $0.02 *$ \\
\hline No & $1-7$ & $3(2)$ & \\
\hline
\end{tabular}

*Mann-Whitney test, **no IQR is calculated; as the number of patients who recieved the drug was less than 4. CYC Cyclophosphamide, AZA Azathioprine, CSA Cyclosporine A

Table 5 Correlation of the Vasculitis Damage Index (VDI) score with some patients' demographic and clinical variables

\begin{tabular}{lll}
\hline Variable & \multicolumn{2}{l}{ VDI in patients with BD $(\boldsymbol{n}=\mathbf{1 0 9})$} \\
\cline { 2 - 3 } & ${ }^{\mathbf{a}_{\mathbf{r}}}$ & ${ }^{*} \mathbf{P}$ \\
\hline Delay in diagnosis & 0.02 & 0.84 \\
BDCAF & 0.15 & 0.13 \\
Age & 0.2 & $\mathbf{0 . 0 3}$ \\
Disease duration & 0.21 & $\mathbf{0 . 0 3}$ \\
Stroke score & 0.09 & 0.8 \\
Duration of eye affection & 0.34 & $\mathbf{0 . 0 0 3}$ \\
\hline
\end{tabular}

${ }^{a}$ Spearman correlation coefficient. * $P$ is significant at $<0.05$. VDI Vasculitis damage index, $B D$ Behçet's disease, $B D C A F$ BD current activity form
It seems expected that longer disease duration and duration of eye involvement may be associated with increased damage, which is the case in our study, as VDI was significantly correlated with disease duration and eye involvement. However, the correlation between VDI and age $(P=0.033)$, may contradict the decreased mortality rate in patients with $\mathrm{BD}$ aged $>35$ years reported by Saadoun et al. [36], In our opinion this decline in mortality after age of 35, may raise an important point, that elderly onset BD patients may show milder disease manifestations as some elderly onset lupus, which is appoint that may require further studies.

In this study, we found that VDI is correlated with most aggressive disease manifestations of BD. However, some damage found in patients with $\mathrm{BD}$ may not be covered by VDI, especially damage related to genital ulcers or venous occlusion, e.g., Budd Chiari syndrome, vena caval thrombosis, and cerebral venous sinus thrombosis. Moreover, the development of venous thrombosis (unless complicated) or recurrent venous thrombosis is excluded in the VDI. In contrast, some items mentioned in VDI may not be of value in patients with $\mathrm{BD}$, such as alopecia and proteinuria. Thus, according to the aforementioned reasons, in our opinion, BD modified specific VDI version as that studied by Piga et al. 2020 and including many modified items of VDI [14], may be needed for better assessment of damage in patients with $\mathrm{BD}$, which must be assessed in further prospective, large scale, longitudinal studies.

Among strengths of our study is that, it is one of the pioneer studies in attempt to evaluate Damage index for $\mathrm{BD}$. On the other hand, study limitations include: we did not assess the inter-rater agreement by evaluating Cohen's kappa and the interclass correlation coefficient (ICC), we also did not correlate VDI with the number of flares, cumulative corticosteroid doses, or delay in immunosuppressive therapy.

Vasculitis is a main pathologic finding in $\mathrm{BD}$, and damage index is required in most rheumatic diseases to quantify damage, aid in the separation of damage from disease activity, and rationalize selection of therapy. Fortunately; a recent damage index for Behçet's disease has been validated "Behçet's syndrome overall damage index (BODI)" most items of which, has been derived from VDI, however further validation is needed for such damage index to be established as concluded by their authors.

\section{Conclusions}

VDI is significantly associated with most disease parameters of $\mathrm{BD}$, except for parameters such as mucocutaneous manifestations and uncomplicated venous thrombosis; however, further studies may be needed to establish and validate VDI derived $\mathrm{BD}$-specific damage index. 


\section{Acknowledgements}

Non applicable.

\section{Authors' contributions}

All authors have participated sufficiently in this work. The authors read and approved the final manuscript.

\section{Funding}

This research did not receive any specific grant from funding agencies in the public, commercial, or not-for-profit sectors.

\section{Availability of data and materials}

All data and materials are available.

\section{Declarations}

\section{Ethics approval and consent to participate}

The study was performed in accordance with the Declaration of Helsinki and approved by the local ethical committee. Informed consent was obtained from the patients.

\section{Consent for publication}

All authors gave their consent for publication.

\section{Competing interests}

All authors declare no conflicts of interest.

\section{Author details}

'Rheumatology and Rehabilitation Department, Cairo University, Cairo, Egypt. ${ }^{2}$ Internal Medicine Department, National Research Center, Cairo, Egypt. ${ }^{3}$ Dermatology and venereology Department, National Research Center, Cairo, Egypt. ${ }^{4}$ Public Health Department, Cairo University, Cairo, Egypt.

Received: 6 January 2021 Accepted: 26 May 2021

Published online: 09 June 2021

\section{References}

1. Protogerou AD, Nasothimiou EG, Sfikakis PP, Tzioufas AG. Non-invasive vascular biomarkers in patients with Behçet's disease: review of the data and future perspectives. Clin Exp Rheumatol. 2017;35 Suppl 108(6):100-7.

2. Schirmer M, Calamia KT, Direskeneli H. Ninth international conference on Behçet's disease, Seoul, Korea, May 27-29, 2000. J Rheumatol. 2001;28(3): 636-9.

3. Davatchi F, Assaad-Khalil S, Calamia K, Crook JE, Sadeghi-Abdollahi B, Schirmer $\mathrm{M}$, et al. The international criteria for Behçet's disease (ICBD): a collaborative study of 27 countries on the sensitivity and specificity of the new criteria. J Eur Acad Dermatol Venereol. 2014;28:338-47.

4. Emmi G, Bettiol A, Silvestri E, Di Scala G, Becatti M, Fiorillo C, et al. Vascular Behçet's syndrome: an update. Intern Emerg Med. 2019;14(5):645-52. https://doi.org/10.1007/s11739-018-1991-y.

5. Desbois AC, Wechsler B, Cluzel P, Helft G, Boutin D, Piette JC, et al. Cardiovascular involvement in Behçet's disease. Rev Med Interne. 2014;35(2): 103-11. https://doi.org/10.1016/j.revmed.2013.12.002.

6. Alibaz-Oner F, Direskeneli H. Management of vascular Behcet's disease. Int J Rheum Dis. 2019;22:105-8. https://doi.org/10.1111/1756-185X.13298.

7. Ketari Jamoussi S, Chaaba H, Ben Dhaou B, Boussema F, Kochbati S, Cherif $\mathrm{O}$, et al. Arterial involvement in Behcet's disease: a series of 7 cases. Tunis Med. 2009;87(9):583-8.

8. Jayne $D$. Challenges in the management of microscopic polyangiitis: past present and future. Curr Opin Rheumatol. 2008;20(1):3-9. https://doi.org/1 0.1097/BOR.0b013e3282f370d1.

9. Mukhtyar C, Flossmann O, Hellmich B, Bacon P, Cid M, Cohen-Tervaert JW, et al. Outcomes from studies of anti-neutrophil cytoplasm antibody associated vasculitis: a systematic review by the European league against rheumatism systemic vasculitis task force. Ann Rheum Dis. 2008;67(7):100410. https://doi.org/10.1136/ard.2007.071936.

10. Seo P, Luqmani RA, Flossmann O, Hellmich B, Herlyn K, Hoffman GS, et al. The future of damage assessment in vasculitis. J Rheumatol. 2007;34(6): 1357-71.

11. Exley AR, Bacon PA, Luqmani RA, Kitas GD, Gordon C, Savage CO, et al. Development and initial validation of the vasculitis damage index for the standardized clinical assessment of damage in the systemic vasculitides. Arthritis Rheum. 1997:40(2):371-80. https://doi.org/10.1002/art.1780400222.

12. Watts RA, Scott DG. Recent developments in the classification and assessment of vasculitis. Best Pract Res Clin Rheumatol. 2009;23(3):429-43. https://doi.org/10.1016/j.berh.2008.12.004.

13. Piga M. Behçet's Disease Overall Damage Index (BODI). https://clinicaltrials. gov/ct2/show/NCT03803462

14. Piga M, Floris $A$, Espinosa $G$, et al. Development and preliminary validation of the Behçet's syndrome overall damage index (BODI). RMD Open. 2020;6: e001192. https://doi.org/10.1136/rmdopen-2020-001192.

15. Hatemi G, Christensen R, Bang D, Bodaghi B, Celik AF, Fortune F, et al. 2018 update of the EULAR recommendations for the management of Behçet's syndrome. Ann Rheum Dis. 2018;77:808-18. https://doi.org/10.1136/a nnrheumdis-2018-213225.

16. Hatemi G, Silman A, Bang D, Bodaghi B, Chamberlain AM, Gul A, et al. EULAR recommendations for the management of Behçet disease. Ann Rheum Dis. 2008;67(12):1656-62. https://doi.org/10.1136/ard.2007.080432 Epub 2008 Jan 31

17. Lawton G, Bhakta BB, Chamberlain MA, Tennant A. The Behçet's disease activity index. Rheumatology. 2004;43(1):73-8. https://doi.org/10.1093/ rheumatology/keg453.

18. Zayed HS, Medhat BM, Seif EM. Evaluation of treatment adherence in patients with Behçet's disease: its relation to disease manifestations, patients' beliefs about medications, and quality of life. Clin Rheumatol. 2019; 38(3):761-8. https://doi.org/10.1007/s10067-018-4344-3.

19. Kural-Seyahi E, Fresko I, Seyahi N, Ozyazgan Y, Mat C, Hamuryudan V, et al. The long-term mortality and morbidity of Behçet syndrome: a 2-decade outcome survey of 387 patients followed at a dedicated center. Medicine (Baltimore). 2003;82(1):60-76. https://doi.org/10.1097/00005792-20030100000006.

20. Silveira LH. Damage assessment in systemic vasculitis. Curr Rheumatol Rep. 2008;10(6):436-41. https://doi.org/10.1007/s11926-008-0071-0.

21. Attia DHS, Abdel Noor RA. Severe Behçet's disease equally affects both genders in Egyptian patients: a multicentre retrospective follow-up study. Reumatismo. 2019;71(4):218-25.

22. El-Garf A, Abdo M, Alkemary A, Mohamed S. Behcet's disease patterns and subsets in a cohort of Egyptian patients. Egypt Rheumatol. 2019;14:135-8. https://doi.org/10.1016/j.ejr.2018.05.006.

23. Cansu DU, Kaşifoğlu T, Korkmaz C. Do clinical findings of Behçet's disease vary by gender?: a single-center experience from 329 patients. Eur J Rheumatol. 2016;3(4):157-60. https://doi.org/10.5152/eurjrheum.2016.038.

24. Wu X, Li G, Huang X, et al. Behcet's disease complicated with thrombosis. A report of 93 Chinese cases. Medicine. 2014;93(28):e263. https://doi.org/10.1 097/MD.0000000000000263.

25. Greco A, De Virgilio A, Ralli M, Ciofalo A, Mancini P, Attanasio G, et al. Behçet's disease: new insights into pathophysiology, clinical features and treatment options. Autoimmun Rev. 2018;17(6):567-75. https://doi.org/10.1 016/j.autrev.2017.12.006.

26. Amigo MC, Goycochea-Robles MV, Espinosa-Cuervo G, Medina G, BarragánGarfias JA, Vargas A, et al. Development and initial validation of a damage index (DIAPS) in patients with thrombotic antiphospholipid syndrome (APS). Lupus. 2015;24(9):927-34. https://doi.org/10.1177/0961203315576858.

27. Saadoun D, Asli B, Wechsler B, Houman H, Geri G, Desseaux K, et al. Longterm outcome of arterial lesions in Behçet disease: a series of 101 patients. Medicine. 2012;91(1):18-24. https://doi.org/10.1097/MD.0b013e3182428126.

28. Yang P, Huang G, Du L, Ye Z, Hu K, Wang C, et al. Long-term efficacy and safety of interferon alpha-2a in the treatment of Chinese patients with Behçet's uveitis not responding to conventional therapy. Ocul Immunol Inflamm. 2019;27(1):7-14. https://doi.org/10.1080/09273948.2017.1384026.

29. Gladman D, Ginzler E, Goldsmith C, Fortin P, Liang M, Urowitz M, et al. The development and initial validation of the systemic lupus international collaborating clinics/American College of Rheumatology damage index for systemic lupus erythematosus. Arthritis Rheum. 1996;39(3):363-9. https://doi. org/10.1002/art.1780390303.

30. Celiker H, Kazokoglu H, Direskeneli H. Conventional immunosuppressive therapy in severe Behcet's uveitis: the switch rate to the biological agents. BMC Ophthalmol. 2018;18(1):261. https://doi.org/10.1186/s12886-018-0929-5.

31. Zaghetto JM, Yamamoto MM, Souza MB, Silva FT, Hirata CE, Olivalves E, et al. Chlorambucil and cyclosporine a in Brazilian patients with Behçet's disease uveitis: a retrospective study. Arq Bras Oftalmol. 2010;73(1):40-6. https://doi.org/10.1590/S0004-27492010000100007. 
32. Goker B, Goker H. Current therapy for Behçet's disease. Am J Ther. 2002;9(5): 465-70. https://doi.org/10.1097/00045391-200209000-00015.

33. Kaklamani VG, Kaklamanis PG. Treatment of Behçet's disease--an update. Semin Arthritis Rheum. 2001;30(5):299-312. https://doi.org/10.1053/sarh.2 001.19819.

34. Hsu CY, Lin MS, Su YJ, Cheng TT, Lin YS, Chen YC, et al. Cumulative immunosuppressant exposure is associated with diversified cancer risk among 14832 patients with systemic lupus erythematosus: a nested casecontrol study. Rheumatology (Oxford). 2017;56(4):620-8. https://doi.org/10.1 093/rheumatology/kew457.

35. Caza T, Oaks Z, Perl A. Interplay of infections, autoimmunity, and immunosuppression in systemic lupus erythematosus. Int Rev Immunol. 2014;33(4):330-63. https://doi.org/10.3109/08830185.2013.863305.

36. Saadoun D, Wechsler B, Desseaux K, Le Thi HD, Amoura Z, Resche-Rigon M, et al. Mortality in Behçet's disease. Arthritis Rheum. 2010;62(9):2806-12. https://doi.org/10.1002/art.27568.

\section{Publisher's Note}

Springer Nature remains neutral with regard to jurisdictional claims in published maps and institutional affiliations.

Ready to submit your research? Choose BMC and benefit from:

- fast, convenient online submission

- thorough peer review by experienced researchers in your field

- rapid publication on acceptance

- support for research data, including large and complex data types

- gold Open Access which fosters wider collaboration and increased citations

- maximum visibility for your research: over $100 \mathrm{M}$ website views per year

At BMC, research is always in progress.

Learn more biomedcentral.com/submissions 